Bio - grafía. Escritos sobre la Biología y su Enseñanza. ISSN 2027-1034

Edición Extraordinaria. p.p. 874 - 880

Memorias del IX Encuentro Nacional de Experiencias en Enseñanza de la Biología y la Educación Ambiental. IV Congreso Nacional de Investigación en Enseñanza de la Biología.

\title{
CARACTERIZACIÓN DE LA ICONOGRAFÍA INCLUIDA EN EL EJE TEMÁTICO RELACIONES ECOLÓGICAS INTERESPECÍFICAS EN LIBROS DE TEXTO DE CIENCIAS DE SÉPTIMO GRADO
}

\section{CHARACTERIZATION OF THE ICONOGRAPHY INCLUDED IN THE THEMATIC AXIS INTERSPECIFIC ECOLOGICAL RELATIONS IN SEVENTH GRADE SCIENCE TEXTBOOKS}

\author{
Paola Gómez Torres ${ }^{1}$ \\ Silvio Fernando Daza Rosales ${ }^{2}$ \\ José Rafael Arrieta Vergara ${ }^{3}$
}

\section{RESUMEN:}

Las ilustraciones que se presentan en los libros de texto, representan una gran importancia como elemento motivador dentro del proceso de enseñanza/aprendizaje y es muy importante explorar este campo para conocerlo en profundidad y posibilitar estrategias de mejoras para su uso en la enseñanza de algunos temas como las relaciones ecológicas interespecíficas, por lo tanto se propone esta investigación que busca caracterizar las iconografías incluidas en las relaciones ecológicas interespecíficas en los libros de textos de séptimo grado. Se propone una investigación de enfoque cualitativo y del tipo descriptivo. Se determinaran tanto el grado de iconicidad y la función que cumplen, teniendo en cuenta las categorías de análisis propuestas por Richaudeau y Alzate. El trabajo se realizara a partir de los textos que siguen los docentes de la Escuela Normal Superior Cristo Rey de Barrancabermeja, Santander.

PALABRAS CLAVES: Ilustraciones, imágenes, iconografía, libros de textos

\section{ABSTRACT:}

The illustrations presented in textbooks, represent an important motivator element within the teaching/learning process and it is very important to explore this field to know it in depth strategies for improvements for use in the teaching of some topics such as ecological relationships interspecific, therefore intends to this research that seeks to characterize the Iconographies in interspecific ecological relationships in the seventh-

\footnotetext{
${ }^{1}$ Instituto Universitario da Paz, Unipaz, Grupo de investigacion en enseñanza de la ciencias y seguridad alimentaria, INYUBA. jazzminpolag@gmail.com

${ }^{2}$ Instituto Universitario da Paz, Unipaz, Grupo de investigacion en enseñanza de las ciencias y seguridad alimentaria, INYUBA. silvio.daza@unipaz.edu.co

${ }^{3}$ Instituto Universitario da Paz, Unipaz, Grupo de investigacion en enseñanza de la ciencias y seguridad alimentaria, INYUBA rafael.arrieta@unipaz.edu.co
} 
Bio - grafía. Escritos sobre la Biología y su Enseñanza. ISSN 2027-1034

\title{
Edición Extraordinaria. p.p. 874 - 880
}

\author{
Memorias del IX Encuentro Nacional de Experiencias en Enseñanza de la Biología y la \\ Educación Ambiental. IV Congreso Nacional de Investigación en Enseñanza de la \\ Biología.
}

grade textbooks. Proposes a qualitative approach and the descriptive research. Both would be determined the degree of iconicity and the role, taking into account the categories of analysis proposed by Richaudeau and Alzate Piedrahíta. The work will take place from the texts that follow the teachers of the school Normal upper Christ King of Barrancabermeja, Santander.

KEY WORDS: Illustrations, images, iconography, textbooks

\section{INTRODUCCIÓN}

Los libros de texto son instrumentos esenciales y representan uno de los pilares básicos sobre los que se sustenta la acción docente. Se considera que son herramientas pedagógicas creadas con el propósito de facilitar el aprendizaje, claves para la ejecución del acto educativo y de los procesos de aprendizaje en las distintas áreas del conocimiento. (Jiménez \& Perales, 2002).

A pesar de los enormes avances tecnológicos, se continúa tomando como referente al libro de texto; que ejerce una gran influencia en el trabajo en el aula, tanto en profesores como en alumnos y en ellos, tiene especial importancia las ilustraciones que apoyan el texto. (Malhue \& Moraga, 2011).

Jiménez y Perales (2002), indican que las ilustraciones llegan a ocupar hasta un $50 \%$ de la superficie del libro de texto y "a pesar de su masiva presencia en todos los materiales escolares, los estudiantes no están habituados a aprender de estas. Tampoco las consideran fuentes serias de información útil". (Llorente, 2000). Inclusive y teniendo en cuenta a Daza (2002), la transmisión acrítica de las imágenes incluidas en los libros de texto, induce a la elaboración de concepciones alternativas en los estudiantes y pueden ser fuente de errores instruccionales. Actualmente existe una prevalencia de la imagen y en concordancia con Llorente (2014) se vive en un entorno dominado por el signo icónico; La imagen tiene un gran poder sugestivo y se asocia automáticamente la visión de un hecho con su existencia y se asocia imagen con realidad. (2014)

Santos (1984) afirma que existe una invasión de imágenes en la vida del hombre actual que lo envuelve y lo aprisiona y en la escuela no se puede ser ajena a esta realidad, no sólo porque dejaría al niño indefenso ante las falacias, las manipulaciones y las influencias de la imagen, sino porque desperdiciaría unos recursos de gran utilidad educativa. Al no hacerse uso de las imágenes puede resultar perjudicial para la enseñanza-aprendizaje de las ciencias siendo las ilustraciones elementos pedagógicos de gran valor pueden contribuir al aprendizaje, aunque en los actuales libros de texto, las ilustraciones tienen una fuerte presencia, se les está subestimando y son más apreciadas por su naturaleza estética que por las funciones didácticas que desempeñan. Al respecto, Casablancas (2001) señala la necesidad de replantear y mejorar esta situación, afirmando que más allá de la función estética-motivadora, se requiere reconceptualizar el valor de la imagen y capitalizarlo en términos de la intencionalidad pedagógica. 


\title{
Bio - grafía. Escritos sobre la Biología y su Enseñanza. ISSN 2027-1034
}

\section{Edición Extraordinaria. p.p. 874 - 880}

\author{
Memorias del IX Encuentro Nacional de Experiencias en Enseñanza de la Biología y la \\ Educación Ambiental. IV Congreso Nacional de Investigación en Enseñanza de la \\ Biología.
}

Los textos de ciencias naturales y el apartado que hace referencia a las relaciones ecológicas, contienen una gran cantidad de ilustraciones que ameritan un análisis para conocer su grado de complejidad, determinar si en realidad desempeñan algún tipo de función didáctica o confirmar que simplemente constituyen un recurso estético-motivador. Explorar el mundo de las imágenes permite conocer más acerca de ellas, y por lo tanto, contribuir en la mejora de su uso en el proceso de enseñanza-aprendizaje de las ciencias; esto con la finalidad de poder sacar ventajas en cuanto al potencial en masa que guardan las ilustraciones.

Según Rigo (2014), la imagen es un soporte funcional que contribuye a: comprender los contenidos abstractos y difíciles de interpretar, aumentar la motivación por aprender y profundizar con lecturas complementarias, presentar nuevos conceptos, promover el recuerdo de contenidos enseñados y aprendidos, fomentar una comunicación auténtica y relacionada con la vida cotidiana en el salón de clases, estimular la imaginación y expresar las emociones, y activar los conocimientos previos. No cabe duda que los elementos icónicos presentes en los libros de texto de ciencias naturales abundan en número, tamaño y color (entre otras de sus tantas características), marcando la diferencia y resultando ser muy útiles en el ejercicio didáctico. Si se conoce cuál es la intención pedagógica de una ilustración y si se le da un uso adecuado, dicho elemento puede proporcionar un mejor resultado en cuanto a los aprendizajes significativos del conocimiento científico.

Las ilustraciones pueden ser aprovechadas al máximo, pero sin el conocimiento de su naturaleza, es un poco complicado. Así mismo, podrían seguir siendo subestimadas y tenidas en cuenta solamente por su belleza estética y lo que es peor, seguirían siendo desaprovechadas, pese a constituir un recurso didáctico elemental para la enseñanzaaprendizaje de las ciencias; sin mencionar que seguirían en desventaja frente al lenguaje verbal, lo que podría resultar contraproducente, ya que la sociedad actual está viviendo el auge de la dimensión icónica.

Hay que romper con la creencia que la ilustración es solo decoración, y comenzar a darle el valor y el uso adecuado dentro del ejercicio pedagógico; pero se requiere comprender más sobre el mundo de las ilustraciones de los libros de texto y sobre las funciones que éstas pueden desempeñar. Una de las características del valor formativo de las ciencias de la naturaleza es que despiertan la capacidad de observación del mundo circundante y con una observación apropiada de las ilustraciones se pueden aprender procesos científicos básicos. Aprender a mirar y ver a través de las ilustraciones fomenta la alfabetización visual (pensar qué significan las imágenes y los objetos, cómo los interpretamos). La imagen tiene un enorme potencial de aprendizaje mediante la observación y son útiles para aproximar al lector al contenido científico, posibilitando la interpretación del mismo de una forma visual, más inmediata que el texto escrito (López, 2015).

Pérez de Eulate, Llorente \& Andrieu (1999) indican que "en el ámbito específico de los libros de ciencias, también resultan habituales los estudios de análisis del contenido y de errores conceptuales presentes en aquellos, quedando prácticamente al margen las 
Bio - grafía. Escritos sobre la Biología y su Enseñanza. ISSN 2027-1034

\title{
Edición Extraordinaria. p.p. 874 - 880
}

\author{
Memorias del IX Encuentro Nacional de Experiencias en Enseñanza de la Biología y la \\ Educación Ambiental. IV Congreso Nacional de Investigación en Enseñanza de la \\ Biología.
}

ilustraciones correspondientes o, cuando se hace, se consideran exclusivamente en relación con algún contenido específico.

A pesar de que las ilustraciones ocupan en los libros de texto de educación primaria y secundaria un $50 \%$ de superficie y de que resultan relativamente frecuentes en el ámbito pedagógico, la importancia que se le concede resulta casi anecdótica. (Jiménez \& Perales, 2002). Son muy importantes y algunos autores, le prestan atención y le dedican tiempo a su estudio por su significado., al respecto, Ossenbach \& Somoza (2003), realizaron un estudio sobre los manuales escolares españoles, haciendo énfasis en la transformación que experimentaron dichos libros; los autores concluyeron que se pasó de la textualidad a la iconicidad, esto quiere decir que anteriormente era el texto escrito el único elemento que predominaba y ahora, comparte considerablemente esa predominancia con la ilustración.

Con este trabajo, se pretende identificar el grado de iconicidad y la función que poseen las ilustraciones de relaciones ecológicas interespecíficas en los libros de texto de séptimo grado y por lo tanto, se plantea la siguiente pregunta de investigación: ¿Cuál es el grado de iconicidad y la función que predomina en las ilustraciones de relaciones ecológicas interespecíficas incluidas en los libros de texto de ciencias naturales de grado séptimo?

Algunos autores como Pérez (1999), Perales y Jiménez (2001), Duchastel (1981), Casablancas (2001) Greca (2002) \& Alzate (1999), han elaborado taxonomías para clasificar las imágenes teniendo en cuenta: tamaño, color, número, función didáctica que desempeñan, ubicación espacial, orientación de las formas en el espacio, énfasis notacional, contenido e información, características y atributos formales, las funciones instructivas, los detalles ampliados, las secciones gráficas, la secuencia didáctica, los grafismos, el recurso estético-motivador, la comunicación visual, la función de la secuencia didáctica, el grado de iconicidad, las etiquetas verbales, la relación con el texto escrito, el contenido científico que las sustenta, entre otras.

Una forma para clasificar las ilustraciones, es la taxonomía que propone Álzate (1999), que tiene en cuenta dos categorías para esto: el grado de iconicidad y las funciones que desempeñan. Esta clasificación es muy sencilla, práctica y concisa y nos servirá de referencia.

\section{METODOLOGÍA}

En esta investigación de enfoque cualitativo, se caracterizarán las ilustraciones de relaciones ecológicas interespecíficas incluidas en los libros de texto de séptimo grado; se especificará el grado de iconicidad y se identificará la función didáctica que predomina en la iconografía estudiada. Se determinarán categorías tanto para el grado de iconicidad (fotografías, dibujos, esquemas) como para la función didáctica (motivación, decorativa, información, reflexión, ejemplo), teniendo en cuenta las categorías de análisis propuestas 
Bio - grafía. Escritos sobre la Biología y su Enseñanza. ISSN 2027-1034

Edición Extraordinaria. p.p. 874 - 880

Memorias del IX Encuentro Nacional de Experiencias en Enseñanza de la Biología y la

Educación Ambiental. IV Congreso Nacional de Investigación en Enseñanza de la Biología.

por Richaudeau y Alzate Piedrahita. Se hará un estudio de caso, utilizando un solo ejemplar.

En este trabajo, las ilustraciones se ordenarán, se describirán y se caracterizarán según el grado de iconicidad y la función que éstas poseen. Se utilizarán cuatro instrumentos para recolectar datos sobre el libro de texto y las ilustraciones de relaciones ecológicas contenidas en él; una tabla estará destinada a consignar los datos más relevantes del libro de texto analizado, y las otras tres, irán dirigidas a consignar la información obtenida de las ilustraciones. Para el caso de las variables o categorías analizadas en las ilustraciones, se utilizarán dos tablas: una para el grado de iconicidad y otra para la función según la escala propuesta por Richaudeau y la clasificación propuesta por Alzate Piedrahita.

\section{RESULTADOS PARCIALES}

Es una investigación que se encuentra en fase de propuesta y ha sido presentado a nivel de idea, en el grupo de investigación en seguridad alimentaria, INYUBA, dentro del marco de la línea de investigación la enseñanza de las ciencias del diseño. Posteriormente se presentó la propuesta para solicitar la autorización para desarrollar el trabajo de campo.

Para dar inicio al trabajo de campo se realizó una etapa de sensibilización en el colegio y con los docentes del área con el fin de obtener de ellos el consentimiento informado para poder desarrollar la fase de campo.

Se está en la etapa de validar el instrumento que se empleara para la toma de información.

\section{REFERENCIAS}

ALZATE PIEDRAHITA, M. V. (1999). ¿Cómo leer un texto escolar?: Texto, paratexto e imágenes. Revista de Ciencias humanas, 20. UTP, Pereira, Colombia.

AMAYA, B. 2008). El progreso en las representaciones de las relaciones interespecíficas en estudiantes de grado cuarto desde las perspectivas de aprendizaje significativo y una modelos mentales. Trabajo de grado para optar el título Licenciado en educación básica con énfasis en ciencias naturales y educación ambiental, 128 p. Universidad de Antioquia, Medellín, Colombia, p. 31.

AMBRÒS PALLARÈS, Alba y BREU PANYELLA, Ramón. Leer la imagen. Texto e imagen, pp. 129-150, en: RUIZ BIKANDI, Uri (coord.) Lengua castellana y literatura. Complementos de formación disciplinar. Ministry of Education y Graó, p. 130, Barcelona, 2011.

CASABLANCAS, S. (2001) En cuanto a las imágenes en textos escolares. Función, relevancia y características desde una perspectiva didáctica, Barcelona, España p. 2 
Bio - grafía. Escritos sobre la Biología y su Enseñanza. ISSN 2027-1034

Edición Extraordinaria. p.p. 874 - 880

Memorias del IX Encuentro Nacional de Experiencias en Enseñanza de la Biología y la

Educación Ambiental. IV Congreso Nacional de Investigación en Enseñanza de la Biología.

DAZA, S. (2002). Los gráficos de los libros universitarios de biología y su influencia en la reproducción de una concepción alternativa sobre la célula. Educación en Ciencias e ingenierías. Universidad de la paz. Vol. $1 \mathrm{~N}^{\circ}$ 2, p.12-15

DUCHASTEL, P. (1981). Illustrations in texts: a retentional role. Programmed Learning and Educational Technology, 18, pp. 11-15.

GRECA, I. M., MOREIRA, M. A., OTERO, M. R. (2002). El uso de las imágenes en textos de física para la enseñanza secundaria y universitaria. Investigações em ensino de ciências - V7(2), pp. 127-154. Brasil.

JIMÉNEZ, J. y PERALES, J. (2002). Las ilustraciones en la enseñanza-aprendizaje de las ciencias. Análisis de libros de texto. Enseñanza de las ciencias, 20(3), 369-386, Granada: p. 369.

LLORENTE CÁMARA, E. (2000). Imágenes en la enseñanza. Departamento de Didáctica de la Expresión Musical, Plástica y Corporal. Revista de psicodidáctica, ISSN 11361034, №. 9, 2000, págs. 119-135.

LLORENTE PUERTA, M. J. La imagen en el proceso constructivista del aprendizaje de español como I2 para neolectores. Accem - Asturias. En: La enseñanza del Español como LE/L2 en el siglo XXI / Narciso Miguel Contreras Izquierdo (ed. lit.), 2014, ISBN 978-84-617-1475-9, págs. 363-372.

LÓPEZ MARTíNEZ, J. D. (2015). Construir una imagen de la ciencia: las ilustraciones de los libros escolares de lectura científica. Actas del XVIII Coloquio de Historia de la Educación. Vol. 2. Sección 3. Universidad de Murcia.

MARTÍNEZ, J. D. L. (2015). Construir una imagen de la ciencia: las ilustraciones de los libros escolares de lectura científica. In Actas del XVIII Coloquio de Historia de la Educación: Arte, literatura y educación (pp. 125-138). Universitat de Vic-Universitat Central de Catalunya.

MALHUE SERRANO, R.\& MORAGA CARRASCO, M. (2011). Análisis taxonómico de los libros de texto para la enseñanza de química en educación media. Revista electrónica diálogos educativos. Número 22. Instituto de Química, Facultad de Ciencias, Pontificia Universidad Católica de Valparaíso. Chile.

OSSENBACH SAUTER, G., \& SOMOZA, M. (2000). Los manuales escolares españoles en la época digital. De la textualidad a la iconicidad. En: Spregelburd, R. y Linares, C. la lectura en los manuales escolares. Textos e imágenes. 2009.

OTERO, M. R., \& GRECA, I. M. R. (2004). Las imágenes en los textos de Física: entre el optimismo y la prudencia. Caderno Brasileiro de Ensino de Física, 21(1), 35-64.

PÉREZ DE EULATE, L., LLORENTE, E., \& ANDRIEU, A. (1999). Las imágenes de digestión y excreción en los textos de primaria. Enseñanza de las Ciencias, 17(2), 165-168. 
Bio - grafía. Escritos sobre la Biología y su Enseñanza. ISSN 2027-1034

Edición Extraordinaria. p.p. 874 - 880

Memorias del IX Encuentro Nacional de Experiencias en Enseñanza de la Biología y la Educación Ambiental. IV Congreso Nacional de Investigación en Enseñanza de la Biología.

RICHAUDEAU, François. (1979). Conception et production des manuels scolaires. Guide practique. Paris: Unesco. p. 51. (Existe versión en español. 1979. Paris: Unesco) p. 82, en Informe final del proyecto de investigación "concepción y evaluación de libros de texto escolar: una herramienta de reflexión y de acción" código: 4-07-12 vicerrectoría de investigaciones, innovación y extensión Universidad Tecnológica de Pereira.

RIGO, D. Y. (2014). Aprender y enseñar a través de imágenes. Desafío educativo. ASRI: Arte y Sociedad. Revista de Investigación, n. 6, Universidad de Málaga, España.

SANTOS GUERRA, M. A. (1984). Imagen y Educación. Madrid: Ediciones Anaya.

SAUTER, G. O. (2000). La Investigación sobre los manuales escolares en América Latina: La Contribución del Proyecto Manes. Historia de la Educación: Revista Interuniversitaria, (19). 